\title{
Researching Recognition of Prior Learning; the significance of assessor's values and beliefs within the Totally Pedagogised Society
}

\section{O'Leary, Phil ${ }^{\mathrm{a}}$ and Ledwith, Ann ${ }^{\mathrm{b}}$}

${ }^{\mathrm{a}}$ Extended Campus, Cork Institute of Technology, Ireland, ${ }^{\mathrm{b}}$ Continuing \& Professional Education, University of Limerick, Ireland.

\begin{abstract}
This research is exploring the values and beliefs of academic assessors around Recognition of Prior Learning (RPL) in order to better understand their mindset and provide a foundation for best practice informed by all actors. An interpretative research design and random stratified sampling allowed for 31 interviews with assessors in an institute of technology setting in Ireland. Bernstein's theories of classification and framing of knowledge and the related ideas of power and control provided the conceptual framework for analysis of the data. The notion of assessors as actors within the totally pedagogised society also supported analysis.

Two themes emerge from the data. The first relates to the primary values and beliefs of assessors around RPL that are related to defending the standards of the formal learning system. The second theme balancing, diverges from this and provides further understanding of positions taken with the assessment of RPL. The research concludes that practitioner networks are necessary to cultivate pedagogic agency for RPL through both the official and pedagogic recontextualisation fields.
\end{abstract}

Keywords: Recognition of Prior Learning; Totally pedagogised society 


\section{Introduction}

Recognition of Prior Learning (RPL) is a key aspect of lifelong learning allowing for the validation of all forms of learning within programmes on national and international frameworks. RPL allows for non-standard admissions or for advanced entry onto programmes. RPL can also be used to award credits for individual modules. While RPL is delivered through a range of approaches within faculties and schools around the world (Starr-Glass, 2012; Werquin, 2010), common to all is assessment which should be "grounded in comparison and equivalency" (Starr-Glass, 2012, p. 1). This research focuses on the perceptions of academic assessors of RPL, the individuals engaged in delivering and assessing modules within approved programmes in higher education.

In practice, assessors of RPL find it can be challenging to provide for and difficult to assess (Cooper \& Harris, 2013; Hewson, 2008). The unique nature of any individual's pathway coupled with the many settings where learning can occur are often challenging for the RPL candidate to identify and for the higher education system to accommodate. The identification, selection and evidencing of an individual's learning for RPL and the presentation of this learning in a form suitable for assessment are complex tasks. The literature states that it is past graduates who most easily approach RPL case preparation, and that RPL is rarely accessed by those marginalised in society, the very candidates it is intended to support (Hamer, 2011; Hewson, 2008).

This research investigates the values and beliefs of academic assessors (Friesen, 2011), arguing that having a better understanding of the common values and beliefs of RPL assessors may provide insight about how to better support RPL assessment and cultivate pedagogic agency for its practice (Cameron, 2006). The rapid changes in society are reflected in Bernstein's (2000) writings, which provide a conceptual framework here to support analysis of data arising from 31 academic assessors within a third level institute of technology in Ireland.

\subsection{Bernstein's theories and the totally pedagogised society}

Bernstein (2000), provides insight into how various forms of knowledge can be structured, transformed and reproduced as curriculum. Bernstein also provides the concept of the totally pedagogised society wherein populations are encouraged to access learning opportunities over a lifetime for various purposes such as life, work, or community involvement (Bernstein, 2000). He presented the totally pedagogised society as a hollow construct, one where trainability and the generic performance mode are used as a means of regulating society, one where various modes of employment and professional identities are rapidly replaced and superseded by other newer emerging identities. Within this realm the 
values and beliefs of the academic assessor of RPL are of key significance where increasingly they are presented with requests for RPL. Despite that fact that many institutions have policies and procedures in place for RPL it is often perceived as a marginal activity (Harris, 2000).

Bernstein (2000), provides the 'pedagogic device' as a concept which provides codes and rules to underpin pedagogic practices. By situating RPL assessment within the pedagogic device this research can more effectively explore how the values and beliefs of the assessor might impact on the outcome for the candidate. Of interest is the field of recontextualisation within the pedagogic device. Robertson (2009), provides a model which includes a 'lens of disposition' as a key element. This research argues that the values and beliefs of the assessor will provide a lens through which they assess the RPL case, and that having an understanding of these are key to supporting the assessor, through acknowledging their viewpoint.

This research is significant in that it is the first time that the values and beliefs of the academic assessor around RPL are investigated. It provides a better understanding of their typical mind-set so that higher education providers will able to take a more holistic approach to providing RPL and be better equipped to respond to the European Commission recommendation of 2012 requesting all higher education to have arrangements in place by 2018 (Council of the European Union, 2012).

\section{Method}

The research took place within an institute of technology in Ireland where a higher education system consisting of both traditional universities and institutes of technology provides a complimentary but distinct provision. Institutes of technology operate on a regional basis and provide more applied programmes than the traditional universities. Ontological and epistemological considerations informed the research, which was designed around the following question;

What are the values and beliefs of academic assessors of RPL, and how might these values and beliefs support pedagogic agency for RPL?

The research design took an interpretative stance in order to explore the realities as experienced by the academic assessor, specifically their values and beliefs as identified around RPL. The analytical framework incorporated pilot testing, review and amendment of the research questions in order to extract suitable data (Bryman, 2012). The researcher acknowledges Heidegger's concept of 'being-in-the-world' and that of researching from within a system (Heidegger, 1996). 
An academic assessor is defined as any individual responsible for the delivery and assessment of modules within higher education programmes. Ethical guidelines were strictly followed. Random stratified sampling resulted in 31 semi-structured interviews with academic assessors from within four faculties in an institute of technology, namely 2 from within the faculty of art of and design; 4 from a maritime background; 10 from business and humanities and 15 from science and engineering. Table 1 presents the interview questions.

Table 1; Interview questions

\begin{tabular}{ll}
\hline Q1 & In considering RPL what do you think are important values ${ }^{1}$ to have? \\
Q2 & Why do you say this? \\
Q3 & What beliefs ${ }^{2}$ do you hold which support RPL? \\
Q4 & Why are these beliefs important? \\
\hline
\end{tabular}

\footnotetext{
Note:

1. A value is that which is held as important and provides a framework as to how we live, think or act (Turner, 2004)

2. Beliefs are 'understandings, premises, or propositions about the world that are felt to be true' (Richardson, 1996, p. 103).
}

\section{Results}

Transcription resulted in 160 pages of text and Nvivo software was used to support initial analysis. A total of 50 and 39 codes were assigned against values and beliefs respectively. Table 2 presents an extract of these results showing the three most dominant codes arising in response to the interview questions. The third and fourth column illustrate the number of sources that arose and the number of times each code occurred within the transcripts.

Bernstein's theories of classification and framing of knowledge coupled with the related notions of power and control provided a conceptual framework to examine the values and beliefs of assessors around non-traditional forms of knowledge and epistemological access for RPL candidates. Following analysis data was grouped into two themes:

1. Defending the standards of the formal learning system,

2. Balancing between acknowledging what the candidate knows and maintaining the standards. 
Table 2. Interview transcripts; most dominant codes.

\begin{tabular}{llcc}
\hline Question & Most dominant codes & Sources & References \\
\hline Q1. Values & Upholding standards of awards & 13 & 24 \\
& No ego in the way non judgemental & 9 & 11 \\
& Fairness or objective & 9 & 12 \\
\hline Q2. \& Why & Maintaining the standards & 16 & 25 \\
& The ability to perform in the world of work & 8 & 8 \\
& Give people a chance & 8 & 12 \\
\hline Q3. Beliefs & Providing alternative pathways into education & 13 & 20 \\
& Value of learning gained non formally and & 9 & 19 \\
& informally & 9 & 11 \\
& RPL is legitimate & 13 & 32 \\
\hline Q4. \& Why & Equal access & 13 & 26 \\
& Trust in the process & 9 & 15 \\
\hline
\end{tabular}

\section{Discussion}

RPL has only occasionally arisen within the literature on Bernstein's theories (Cameron, 2006), yet it is deserving of consideration. The values and beliefs of the actors within RPL are key to understanding the complex interactions between people.

As reported in Table 2 the primary values and beliefs of academic assessors as they relate to RPL are strongly aligned around defending the standards of the formal learning system. This came across clearly in the data and is to be expected. All of the assessors (A1 to A31) interviewed, believe that RPL must never devalue a qualification, as the following comments extracted from the interview transcripts illustrate:

A5 "It is to uphold the standards of the college, the educational standards must always be met. That is really important".

A8 "Again a third level education, most people would love to have it. A lot of people cannot have it, you know it costs a lot of money, so it is an honour and a privilege to have a qualification, and not to be taking it for granted really by people who say, 'lets find a shortcut'". 
A21 "The comparison of standards is very important, but not only that, and the practical, theoretical, but also the cultural dimension of where the applicant is coming from.

Assessors strive to uphold the standards as expected by society and their values and beliefs reflect this in order to deliver graduates with the ability to participate successfully in life and work (Massaro, 2010).

Aside from defending the standards, what is compelling in Table 2 however is that half of the data arising from the interviews is around balancing between the standards and acknowledging what the candidate knows. This is significant within the totally pedagogised society and will be further explored here. The assessor is caught between the traditional approaches of the formal learning system when assessing RPL cases and the unique and diverse nature of non-formal and informal learning and requires support to develop capacity around its evaluation.

A3 "So there are individuals who have obtained learning and are making a contribution to society but for which it is not acknowledged, and if it was acknowledged it would give them more versatility and possibilities to maybe move around in the workforce".

A9 "It is important to assure them that there are different paths to learning".

A31 "I would see that I sit between both of these, support and gatekeeper".

The significant amount of data around the notion of balancing is an unexpected result, however the institute of technology setting may explain why this aspect is so strong. In the totally pedagogised society, the production and distribution of knowledge are essential elements of economic performance. The academic assessor is expected to be a key actor, updating curricula to incorporate emerging knowledge in a form available for pedagogic discourse and evaluation in order to satisfy market demands for trainability (Bonal \& Rambla, 2003). The rapid pace of change within the workplace, and the constant nature of this change acts to place the assessor, "in an uncertain position between knowledge and pedagogy" (Bonal \& Rambla, 2003, p. 180). This results in an uneasy reality for the assessor who is called upon to deliver in more responsive, flexible ways and increasingly to deliver the capability for carrying out other forms of assessment.

The comparison of the RPL case with the standards of the frameworks and their evaluation to establish equivalency involves reaching out, taking a different viewpoint, being open to the unexpected. The frameworks act to provide protection in their own right. The ability to step aside from traditional curricula and to value the inherent tension that will naturally arise will support RPL assessment (Starr-Glass, 2012). This balancing capacity is a key ability for successful RPL provision (Starr-Glass, 2012). Nurturing this ability with 
appropriate supports may support the cultivation of pedagogic agency for RPL practice amongst academic assessors.

\section{Conclusion}

Cultivating pedagogic agency for RPL should most effectively take a dual approach through both the official and the pedagogic recontextualisation fields. Academic assessors require significant support. This research suggests practitioner networks operating at a micro and macro level incorporating supports where practices are shared and scenarios relayed will act to reassure and build capacity with RPL assessment. It can be argued here that the institute of technology setting of this research piece is within the totally pedagogised society, responsive in general to RPL and accustomed to rapidly changing higher education provision. It can also be argued that a more traditional university setting may result in a different data set and is worthy of further exploration.

The values and beliefs of RPL assessors act to support their real-time evaluation of nonformal and informal learning. The rapid pace of renewal and reinvention within higher education more often results in assessors meeting requests for RPL and subsequently managing their evaluation on their own terms (De Graaf, 2013). Researching the values and beliefs of the academic assessor provides insight into how to cultivate pedagogic agency for RPL practice in a real and supportive way, and open up debate about the inherent difficulties within RPL practice in general. Such debate, grounded in practice, and arising from practitioners within the pedagogic recontextualisation field will cultivate links across the formal learning system.

\section{References}

Bernstein, B. (2000). Pedagogy, sybolic control and identity; Theory research and critique (2nd ed.). Lanham, MD: Rowman \& Littlefield.

Bonal, X., \& Rambla, X. (2003). Captured by the Totally Pedagogised Society: teachers and teaching in the knowledge economy. Globalisation, Societies and Education, 1(2), 169-184.

Bryman, A. (2012). Social Research Methods (4th ed.). Oxford: Oxford University Press.

Cameron, R. (2006). RPL and the disengaged learner: the need for new starting points. In P. Andersson \& J. Harris (Eds.), Re-theorising the Recognition of Prior Learning. Leicester: NIACE.

Cooper, L., \& Harris, J. (2013). Recognition of prior learning: exploring the 'knowledge question'. International Journal of Lifelong Education, 32(4), 447-463. 
Council of the European Union. (2012). Council recommendation of 20 December 2012 on the validation of non-formal and informal learning. Official Journal of the European Union. Brussels: Council of the European Union.

De Graaf, F. (2013). The interpretation of a knowledge claim in the Recognition of Prior Learning (RPL) and the impact of this on RPL practice. Studies in Continuing Education, 36(1), 1-14.

Friesen, N. (2011). Endword: Reflections on research for an emergent field In J. Harris, M. Brier \& C. Wihak (Eds.), Researching the Recognition of Prior Learning; International Perspectives. Leicester: NIACE.

Hamer, J. (2011). Recognition of prior learning (RPL): can intersubjectivity and philospohy of recgnition support better equity outcomes? Australian Journal of Adult Learning, 51(December), 90-109.

Harris, J. (2000). RPL: Power, pedagogy and possibility. Pretoria: Human Sciences Research Council.

Heidegger, M. (1996). Being and Time. New York: State University of New York Press.

Hewson, J. (2008, 3-4th April). RPL policy to practice: why the reticence of practitioners to engage? Paper presented at the Australian Vocational Education and Training Research Association (AVETRA) 11th Annual Conference, Adelaide.

Massaro, V. (2010). Cui bono? The relevance and impact of quality assurance. Journal of Higher Education Policy and Management, 32(1), 17-26.

Richardson, V. (1996). The role of attitudes and beliefs in learning to teach. In J. Sikula (Ed.), Handbook of research on teacher education. New York: McMillan.

Robertson, I. (2009). Teachers as active agents in recontextualising pedagogic spaces. Paper presented at the Same places; different spaces, Auckland, NZ.

Starr-Glass, D. (2012). Partial Alignment and Sustained Tension: Validity, Metaphor, and Prior Learning Assessment. PLA Inside Out: An International Journal on Theory, Research and Practice in Prior Learning Assessment, 1(2).

Turner, M. (2004). Values \& beliefs in mentoring. Coach the Coach, (7). Retrieved from http://www.mentoringforchange.co.uk/pdf/CtC\%20-\%20Values.pdf

Werquin, P. (2010). Recognition of Non-Formal and Informal Learning; Outcomes, Policies and Practices. Paris: OECD. 